\title{
O DESEMPENHO DA LINGUAGEM E ORGANIZAÇÃO ESPAÇO-TEMPORAL EM CRIANÇAS COM SÍNDROME DE DOWN POR MEIO DA ESCALA DE DESENVOLVIMENTO MOTOR
}

\author{
Mileide Cristina Stoco de Oliveira; Fabiana Araújo Silva; Tânia Cristina Bofi²; Augusto Cesinando \\ de Carvalho². \\ 'Universidade Estadual Paulista - UNESP, Departamento de Fisioterapia, Presidente Prudente - SP.E-mail: \\ cristina.mileide@gmail.com
}

\section{RESUMO}

As principais características cognitivas encontradas em indivíduos com Síndrome de Down (SD) vinculam-se ao desequilíbrio na função reguladora dos genes, que provoca anormalidades estruturais e funcionais no sistema nervoso. Destacam-se alterações sinápticas devido à diminuição da densidade no córtex sensório-motor, o que influenciará na deficiência intelectual e na motricidade. $O$ objetivo deste estudo foi avaliar o desempenho da linguagem e organização espaço-temporal em crianças com SD. Participaram deste estudo dezoito crianças com SD, com a média de idade de $6 \pm 2,04$ anos, frequentadoras do Laboratório de Psicomotricidade e Centro de Estudos e Atendimentos em Fisioterapia e Reabilitação da Universidade Estadual Paulista (FCT/UNESP) de Presidente Prudente. Utilizou-se como instrumento a Escala de Desenvolvimento Motor, que avalia o desenvolvimento motor de crianças de 2 a 11 anos de idade. Conclui-se que das crianças avaliadas somente uma conseguiu realizar o teste respectivo a sua idade cronológica.

Palavras-chave: Síndrome de Down; Destreza Motora; Desenvolvimento Infantil, Crianças; Avaliação.

\section{PERFORMANCE OF LANGUAGE AND SPACE-TEMPORAL ORGANIZATION IN CHILDREN WITH DOWN SYNDROME THROUGH THE MOTOR DEVELOPMENT SCALE}

\begin{abstract}
This article discusses about the main cognitive characteristics found in individuals with Down syndrome (DS) is the unbalance in the function of regulatory genes, which causes structural and functional abnormalities in the nervous system. Detail synaptic changes due to reduction density in the sensorimotor cortex, which will influence the motor and intellectual disabilities. The purpose of this study was to performance of language and space-temporal organization in of children with DS. The study included eighteen children with DS, the average age of $6 \pm 2,04$ years, attending the Psychomotor Laboratory and the Center for Studies and Treatment in Physical Therapy and Rehabilitation, Universidade Estadual Paulista (FCT / UNESP), Presidente Prudente. Was used as a tool to Motor Development Scale, which evaluate motor development of children 2-11 years old. We conclude that only one of the children tested could conduct its test their chronological age.
\end{abstract}

Keywords: Down Syndrome; Motor Skills; Child Development, Child; Evaluation. 


\section{INTRODUÇÃO}

A Síndrome de Down é caracterizada pela trissomia do cromossomo 21 , sendo a síndrome genética de maior incidência e tem como principal consequência à deficiência intelectual ${ }^{1}$. Sua incidência é de 1,13 para cada 1000 nascidos vivos, tendo em média 8.000 novos casos por ano no Brasil, abrangendo aproximadamente $18 \%$ do total de deficientes intelectuais em instituições especializadas no Brasil ${ }^{2}$.

Dentre as características fisiológicas e cognitivas da Síndrome de Down, se destacam a frouxidão ligamentar e hipotonia muscular que ocorrem devido à carência de impulsos descendentes que demandam 0 conjunto dos neurônios motores da medula espinhal ${ }^{2,3}$. Ainda há alterações sinápticas devido à diminuição da densidade no córtex sensório-motor, o que influenciará na deficiência intelectual e na motricidade ${ }^{2}$.

Também há anormalidades na estrutura e função do sistema nervoso. Todos os neurônios formados sofrem alterações na sua estrutura e organização da comunicação entre eles, acarretando em dificuldades de direcionar e selecionar estímulos pela fadiga das conexões, porque há uma deficiência das ramificações dendríticas ${ }^{2}$.

Além disso, o cérebro apresenta hipoplasia nos lóbulos frontais, occipitais, e temporal, e alguns casos observa-se até a diminuição do corpo caloso, do hipocampo e da comissura anterior ${ }^{4}$. Os giros $e$ as circunvoluções cerebrais são mais simples ${ }^{3}$. Ao mesmo tempo, a conduções nervosas centrais, periféricas e os processamento central estão mais lentos, causando atraso no aparecimento dos ajustes posturais ${ }^{2}$.

O cerebelo na Síndrome de Down apresenta hipoplasia e hipoplasticidade, interferindo na manutenção do equilíbrio, dificuldades de adaptação a ambientes mutáveis e na realização de movimentos corporais, acarretando atraso na aquisição dos marcos motores ${ }^{2,5}$.

Todas essas alterações no sistema nervoso afetam a instalação e consolidação das conexões de redes nervosas, necessárias para estabelecer mecanismos de memória, atenção, pensamento abstrato, capacidade de correlacionar e analisar ${ }^{3}$. Além de causar várias disfunções psicomotoras de tonicidade, postura, praxias e somatognosia ${ }^{5}$.

A hipotonia muscular também contribui para alterações no desenvolvimento motor e do esquema corporal, consequentemente no controle postural $^{3,6}$, contribuindo para atrasos nos principais marcos do desenvolvimento motor $^{1}$.

Além do atraso nas questões motoras, a criança com Síndrome de Down apresenta dificuldades de adaptação social, de 
integração perceptiva, de memória, cognitivas, e proprioceptivas devido às alterações neurológicas ${ }^{1,7}$. Sendo que as habilidades motoras estão vinculadas ao desenvolvimento da percepção do corpo, espaço e tempo ${ }^{8}$.

Crianças com Síndrome de Down tendem a apresentar atrasos nessas áreas, uma vez que a percepção do mundo tem base no conhecimento do próprio corpo, que serve como ponto de referência para o desenvolvimento e crescimento das percepções de tempo e espaço. E como a organização espaço-temporal é fundamental para o processo de aprendizagem acadêmica é importante avaliá-las ${ }^{8}$.

Existem diversas escalas que avaliam o desenvolvimento motor de uma criança, essas escalas são instrumentos fundamentais na verificação do desenvolvimento motor ${ }^{11}$. Dentre elas destaca-se a Escala de Desenvolvimento Motor (EDM) ${ }^{10}$. A EDM é composta por uma bateria de testes que avalia o desenvolvimento motor de crianças dos 2 aos 11 anos de idade que apresentam ou não dificuldades na aprendizagem escolar; atrasos no desenvolvimento neuropsicomotor; alterações neurológicas, intelectuais, sensoriais, problemas na fala, escrita ou cálculo; e ainda, crianças com problemas de conduta, como hiperatividade.

Neste contexto, o presente estudo teve como objetivo avaliar a linguagem e a organização espaço-temporal em crianças com diagnóstico de Síndrome de Down.

\section{MÉTODOS}

O presente estudo trata-se de uma pesquisa do tipo descritiva analítica, o qual avaliou 18 crianças ( 6 meninos e 12 meninas, com média de idade de $6 \pm 2,04$ anos) apresentando diagnóstico clínico de Síndrome de Down do tipo trissomia 21, frequentadoras do Laboratório de Psicomotricidade e Centro de Estudos e Atendimentos em Fisioterapia e Reabilitação da Universidade Estadual Paulista (FCT/UNESP) de Presidente Prudente/SP.

Os pais e/ou responsáveis das crianças assinaram o Termo de Consentimento Livre e Esclarecido aprovado pelo Comitê de Ética em Pesquisa da Faculdade de Ciências e Tecnologia - FCTUNESP. O estudo foi aprovado pelo Comitê de Ética em Pesquisa (CEP) da Faculdade de Ciências e Tecnologia - FCT/UNESP, Campus de Presidente Prudente, cujo número do CAAE: 25887913.0.0000.5402.

A avaliação do desenvolvimento motor foi realizada por meio da Escala de Desenvolvimento Motor (EDM). A EDM é composta por uma bateria de testes que avalia o desempenho motor nas seguintes áreas: motricidade fina, motricidade global, equilíbrio, esquema corporal/rapidez, organização espacial, linguagem/organização 
temporal e lateralidade de crianças dos 2 aos 11 anos de idade. Os resultados permitem traçar o perfil motor da criança ${ }^{10}$.

Após aplicação dos testes motores de forma individualizada, foram realizados os cálculos da idade motora (IM) de cada componente, idade motora geral (IMG), idade positiva (IP) / idade negativa (IN), quociente de desenvolvimento de cada componente (QM) e quociente motor geral (QMG). A idade motora (IM) é calculada em meses, de acordo com os acertos alcançados pela criança em cada teste. Idade motora geral (IMG) é o resultado da soma das idades motoras e divisão deste valor pela quantidade das idades motoras avaliadas ${ }^{10}$.

A idade positiva (IP) ou negativa (IN) é dada pelo seguinte cálculo: IMG - IC = - IN / IMG $-\mathrm{IC}=+\mathrm{IP}$. O quociente motor geral (QMG) de cada componente é dado pela multiplicação por 100 do valor da divisão da idade motora pela idade cronológica (IC), da seguinte forma: QMG (\%) = IMG x $100 /$ IC. Em posse do valor do QMG e do perfil motor pode-se classificar o desenvolvimento motor da criança em muito superior (130 ou mais); superior (120-129); normal alto (110-119); normal médio (90-109); normal baixo (8089); inferior (70-79) e muito inferior (69 ou menos). Através dessa avaliação é possível detectar e identificar se há lacunas do desenvolvimento motor, através de dados obtidos nos testes ${ }^{10}$.
Os dados serão apresentados em porcentagem e de acordo com o quociente motor de cada área avaliada e depois será apresentada a média das idades negativas de cada área avaliada.

\section{RESULTADOS}

Das crianças avaliadas na Organização Espacial somente uma conseguiu realizar o teste respectivo a sua idade cronológica. Sendo que destas crianças $83,33 \%$ teve seu desempenho classificado pela escala como muito inferior, $11,11 \%$ teve seu desempenho classificado como normal baixo e 5,55\% teve seu desempenho classificado como inferior. Nessa área a média da idade negativa foi de $3 \pm 1,69$ anos.

Já na Linguagem/Organização Temporal somente uma conseguiu realizar o teste respectivo a sua idade cronológica. Sendo que destas crianças $94,44 \%$ teve seu desempenho classificado pela escala como muito inferior e $5,55 \%$ teve seu desempenho classificado como normal baixo. E a média da idade negativa foi de $4 \pm 1,98$ anos.

Os resultados do desempenho de cada criança nas duas áreas avaliadas e comparados a sua idade cronológica estão expostos no Gráfico 1, sendo possível verificar que a maior parte das crianças avaliadas apresentaram maiores déficits na área da Linguagem/ Organização Temporal. Também é possível verificar que as crianças 
com maior a faixa etária apresentaram um déficit maior.

Por sua vez, o Gráfico 2 mostra o Quociente Motor das áreas avaliadas e evidencia mais uma vez, que as crianças apresentam maiores déficits na área da Linguagem/Organização Temporal.

\section{Comparação da Idade Cronológica com a idade nas áreas avaliadas}

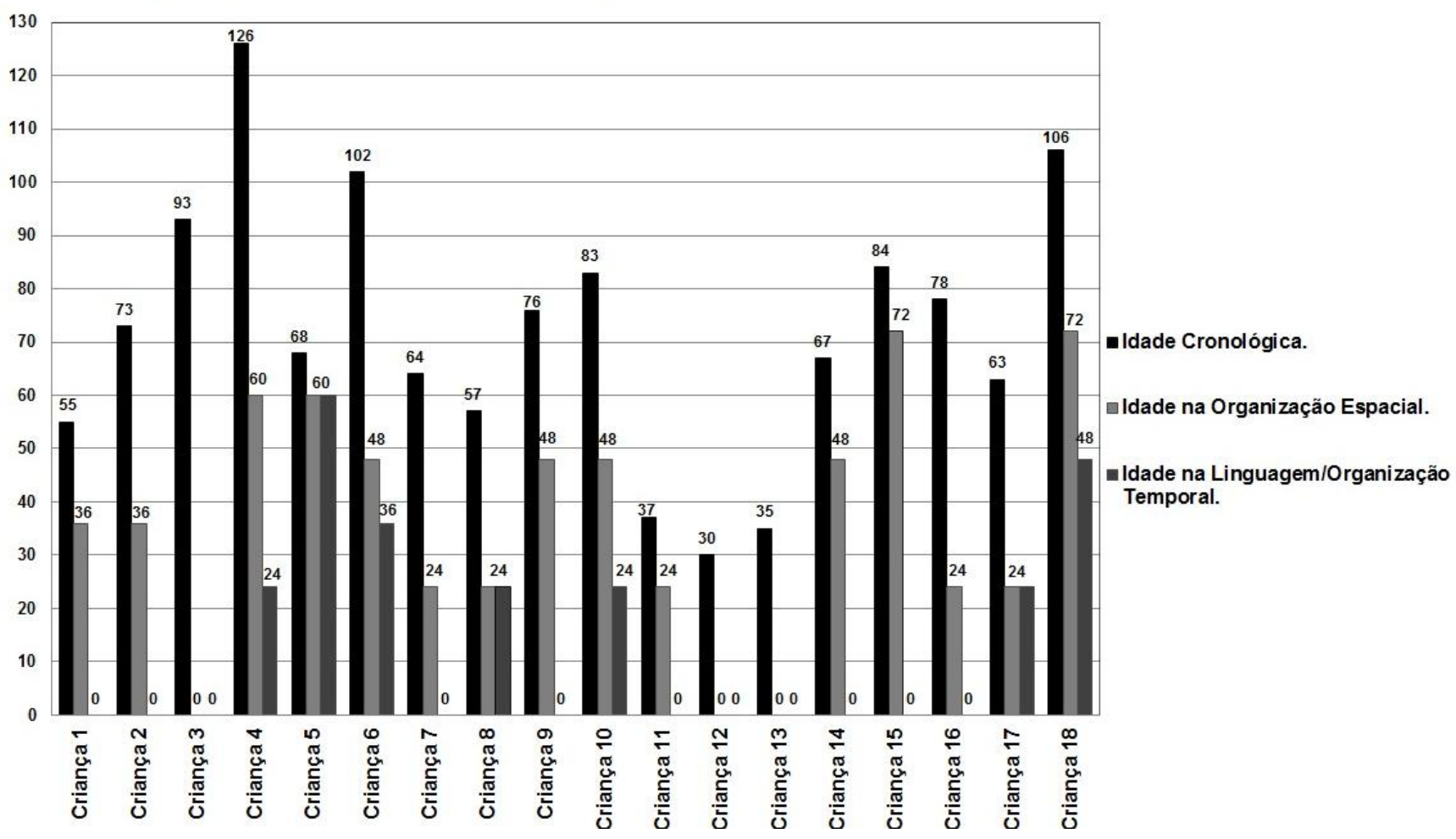

Figura 1. Comparação da idade cronológica com a idade motora na Organização Espacial e na Linguagem/Organização Temporal em meses. 


\section{Quociente Motor das áreas avaliadas}

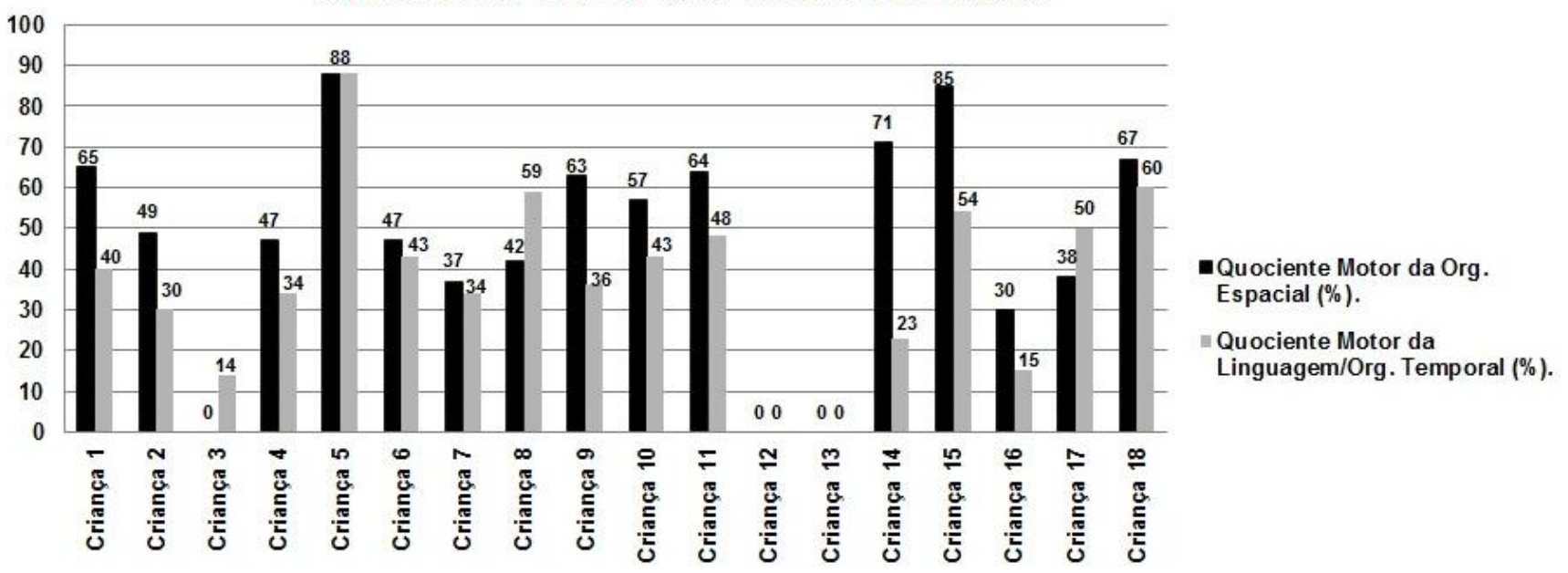

Figura 2. Valores dos Quocientes Motores da Organização Espacial e Linguagem/Organização Temporal em porcentagem.

\section{DISCUSSÃO}

Crianças com Síndrome de Down tendem a apresentar déficits em áreas do desenvolvimento motor, como no estudo realizado por Santos et al. ${ }^{12}$, cujo quociente motor em todas as áreas avaliadas (motricidade global, equilíbrio, motricidade fina, esquema corporal, organização temporal /linguagem e organização espacial), foi a classificado como muito inferior, igualmente ao quociente motor das áreas avaliadas nesse estudo.

Outro estudo Sampaio et al. $^{9}$, apontou que crianças com Síndrome de Down apresentam déficits em todas as áreas avaliadas, principalmente na organização temporal, pois possuem dificuldade para identificar a duração de intervalos e períodos, nesse estudo também foi possível verificar que a área da linguagem/ organização temporal foi a área que as crianças avaliadas apresentaram maiores déficits.

Freire et al. $^{4}$, demonstraram em seu estudo que a linguagem é uma das áreas que crianças com Síndrome de Down, apresentam mais déficit, pois há grandes déficits nos aspectos fonológicos e sintáticos. Como se pode observar nesse estudo e também no estudo de Medina et al. ${ }^{8}$, há evidências que, quanto maior a faixa etária das crianças maior e o déficit motor em crianças com Síndrome de Down. Esses déficits, se persistirem, podem interferir no desenvolvimento de habilidades motoras futuras como na aprendizagem escolar ${ }^{8}$.

\section{CONCLUSÃO}

Concluíu-se que, crianças com Síndrome de Down apresentam déficits nas áreas da linguagem e da organização espaço- 
temporal, sendo que os maiores déficits foram encontrados na área da linguagem/organização temporal. Também foi possível verificar que as crianças com maior a faixa etária apresentaram um déficit maior. Apesar do tamanho da amostra ser reduzido, nosso estudo evidenciou a viabilidade dos resultados encontrados na avaliação.

\section{REFERÊNCIAS}

1. Mattos BM, Bellani CDF. A Importância da estimulação precoce em bebês portadores de Síndrome de Down: revisão de literatura. Rev Bras Terap e Saúde [Internet] 2010; 1(1): 5163.Disponível em: http://www.omnipax.com.br/RBTS/artigos/v 1n1/RBTS-1-1-5.pdf.

2. Silva MFMC, Kleinhans ACS. Processos cognitivos e plasticidade cerebral na Síndrome de Down. Rev Bras Ed Esp. 2006; 12(1): 123-38.

DOI: http://dx.doi.org/10.1590/S1413$\underline{65382006000100009}$.

3. Corrêa JCF, Oliveira AR, Oliveira CS, Corrêa FI. A existência de alterações neurofisiológicas pode auxiliar na compreensão do papel da hipotonia no desenvolvimento motor dos indivíduos com síndrome de Down? Fisioterapia e Pesquisa 2011; 18(4): 337-81. DOI: http://dx.doi.org/10.1590/S1809$\underline{29502011000400014}$

4. Freire RCL, Duarte NS, Hazin I. Fenótipo neuropsicológico de crianças com síndrome de Down. Psicologia em Revista 2012; 18(3): 354-72. DOI: http://dx.doi.org/10.5752/P.16789563.2012V18N3P354.
5. Meneghetti $\mathrm{CHZ}$, Porto $\mathrm{CHS}$, Iwabe $\mathrm{C}$, Poletti S. Intervenção da equoterapia no equilíbrio estático de criança com síndrome de Down. Rev Neurocienc. [Internet] 2009; 17(4): 392-96. Disponível em: http://neren.com.br/site/artigos/018.pdf.

6. Pôrto CMV, Ibiapina SR. Ambiente aquático como cenário terapêutico ocupacional para o desenvolvimento do esquema corporal em Síndrome de Down. RBPS 2010; 23(4): 38994.DOI:

http://dx.doi.org/10.5020/18061230.2010. p389

7. Lima SC, Sousa C, Leite RBC, Alchieri JC, Silva RH, Albuquerque FS. Síndrome de Down: estudo exploratório da memória no contexto de escolaridade. Ciências \& Cognição [Internet] 2009; 14 (2): 35-46. Disponível em: http://www.cienciasecognicao.org/pdf/v14 2/m120 09.pdf.

8. Medina J, Rosa GKB, Marques I. Desenvolvimento da organização temporal de crianças com dificuldades de aprendizagem. Rev da Educação Física/UEM 2006; 17(1): 107-16. DOI: http://dx.doi.org/10.4025/reveducfisv1 7n1p107-116.

9. Sampaio PLG, Frnaklin DV, Freire KLM, Pedroso NS. Perfil motor de crianças com síndrome de Down entre 08 e 11 anos de idade na APAE de Santarém/PA. Apae Ciência [Internet] 2013; 1(2):37-54. Disponível em: http://apaeciencia.org.br/index.php/revista/ article/view/35/21.

10. Rosa Neto F. Manual de avaliação motora. 1. ed. Porto Alegre: Artmed; 2002.

11. Bertapelli F, Silva FF, Costa LT, Gorla JI. Desempenho motor de crianças com Síndrome de Down: uma revisão sistemática. J Health Sci Inst. [Internet] 2011; 29(4):28084.Disponível em: http://www.unip.br/comunicacao/publicaco 
es/ics/edicoes/2011/04 outdez/V29 n4 201 1 p280-284.pdf.

12. Santos APM, Weiss SLI, Almeida GMF. Avaliação e intervenção no Desenvolvimento Motor de uma criança com Síndrome de Down. Rev Bras Ed Esp. 2010; 16(1): 19-30. DOI: $\quad$ http://dx.doi.org/10.1590/S1413$\underline{65382010000100003 .}$.

Recebido para publicação em 19/08/2014

Revisado em 28/08/2014

Aceito em 15/09/2014 